\title{
Consequences of Soluble ICAM-1 N-Glycan Alterations on Receptor Bind- ing and Signaling Kinetics in Mouse Astrocytes
}

\author{
Thomas Schürpf $^{\ddagger} *$, Nico Callewaert ${ }^{\S, \#}$, Matthias J.T. Meyer ${ }^{\ddagger}$, Christian Tränkle ${ }^{\dagger}$, Wouter Laroy ${ }^{\natural}$, \\ Richard D. Cummings $\|$ and Vivianne I. Otto ${ }^{*}$
}

\begin{abstract}
${ }^{\sharp}$ Institute of Pharmaceutical Sciences, ${ }^{\S}$ GlycoINIT and Institute of Microbiology, ETH Zurich, Switzerland, ${ }^{\#}$ Unit for Molecular Glycobiology and "FAMB, Department for Molecular Biomedical Research, Ghent University and VIB, Ghent, Belgium, ${ }^{\dagger}$ Department of Pharmacology and Toxicology, Institute of Pharmacy, University of Bonn, Germany, "Department of Biochemistry, Emory University School of Medicine, Atlanta, GA 30322
\end{abstract}

\begin{abstract}
Soluble intercellular adhesion molecule-1 (sICAM-1) is elevated in the cerebrospinal fluid of patients with severe brain trauma and mouse sICAM-1 induces the production of macrophage inflammatory protein-2 (MIP-2) in mouse astrocytes. The production of MIP-2 is greatly enhanced when sICAM-1 contains sialylated complex-type N-glycans (sICAM-1-CT) as produced by Chinese hamster ovary (CHO) cells. By contrast, sICAM-1 from the Lec1 mutant of CHO cells (sICAM-1-HM), containing only high mannose-type $\mathrm{N}$-glycans, is relatively inactive. Here we show that the Nglycans of sICAM-1-CT are mostly $\alpha 2,3$-sialylated bi-, tri-, and tetraantennary complex-type structures with varying amounts of core fucosylation. Unexpectedly, sICAM-1-CT and sICAM-1-HM bound equivalently to mouse astrocytes. Enhanced MIP-2 induction by sICAM-1-CT was associated with a more rapid, higher level, and prolonged MIP-2 response as well as sICAM-1-CT accumulation at the plasma membranes of mouse astrocytes. These results show that glycosylation of sICAM-1 contributes to its signaling properties at the astrocyte cell surface, and suggest that altered glycosylation which might arise as a result of inflammation could regulate the bioactivity of sICAM-1.
\end{abstract}

\section{INTRODUCTION}

Intercellular adhesion molecule (ICAM)-1 is a transmembrane glycoprotein comprising five heavily glycosylated extracellular immunoglobulin-like domains [1]. ICAM1 is also found as a soluble glycoprotein (sICAM-1) consisting of the extracellular part of ICAM-1 [2]. Under normal conditions, ICAM-1 is expressed at low levels on the surface of cells involved in immune responses, such as endothelial cells, lymphocytes, and macrophages, and sICAM-1 is found at low concentrations in plasma, cerebrospinal fluid, and sputum [2-4]. Both ICAM-1 expression and sICAM-1 levels are strongly increased in response to immune challenges and injury [5-8]. The number of ICAM-1-positive vessels and the sICAM-1 levels in cerebrospinal fluid are strongly elevated after severe traumatic brain injury [7,9-11].

The best known biological function of ICAM-1 on vascular endothelial cells is to bind the leukocyte integrins $\alpha_{L} \beta_{2}$ and $\alpha_{M} \beta_{2}$ on activated leukocytes leading to firm leukocyte adhesion and subsequent extravasation $[12,13]$. Major group rhinoviruses use ICAM-1 as their adhesion receptor on nasal epithelium $[14,15]$. The biological function of circulating sICAM-1 is incompletely understood. sICAM-1 has been described as a competitive inhibitor of leukocyte adhesion to endothelial cells [16-18] and of rhinovirus adhesion to nasal mucosa [19]. Other studies suggest that sICAM-1 may have signaling functions. In this respect, sICAM-1 has been

*Address correspondence to this author at the Immune Disease Institute, Harvard Medical School, 200 Longwood Avenue, Boston, MA 02115, USA; Tel: +1 (617) 278-3223; Fax: +1 (617) 278-3232;

E-mail: schurpf@idi.harvard.edu shown to possess angiogenic activity [20], to promote tumor growth [21], to enhance the production of the cytokines tumor necrosis factor (TNF)- $\alpha$, interferon- $\gamma$, and interleukin- 6 during the mixed lymphocyte response [22], and to induce the production of the CXC chemokine macrophage inflammatory protein (MIP)-2 in primary mouse astrocytes $[9,23,24]$. Induction of chemokine production by sICAM-1 in astrocytes may be involved in the inflammatory response to severe brain trauma [24]. The signaling function of sICAM-1 during the mixed lymphocyte response is mediated by $\alpha_{\mathrm{L}} \beta_{2}$. By contrast, angiogenesis and the induction of MIP2 production in astrocytes seem to be mediated by as yet undefined sICAM-1 receptors, since neither endothelial cells nor astrocytes express ICAM-1-binding $\beta_{2}$ integrins [25,26].

Binding of human ICAM-1 to $\alpha_{L} \beta_{2}$ and $\alpha_{M} \beta_{2}$ is differentially affected by $\mathrm{N}$-glycosylation. While binding to $\alpha_{\mathrm{L}} \beta_{2}$ is unaffected by glycosylation, binding to $\alpha_{M} \beta_{2}$ is hindered when complex-type $\mathrm{N}$-glycans are present on the third Iglike domain of human ICAM-1 [27]. In contrast, the MIP-2inducing activity of mouse sICAM-1 in primary mouse astrocytes is enhanced by sialylated complex-type $\mathrm{N}$-glycans as produced by Chinese hamster ovary ( $\mathrm{CHO})$ cells [24]. The mechanisms underlying enhancement of biological effects by glycosylation are largely unexplored. The aim of the present study was therefore to define the structures of the complextype N-glycans present on sICAM-1 from $\mathrm{CHO}$ cells (sICAM-1-CT) and to explore the mechanisms by which these glycans enhance MIP-2 induction in cultured astrocytes.

To define the structures of the sialylated complex-type $\mathrm{N}$-glycans of mouse sICAM-1-CT, we used a previously published method based on the electrophoretic analysis of 
enzymatically released, fluorescently labeled N-glycans before and after treatment with various exoglycosidases [28]. More than $90 \%$ of the N-glycans were found to be sialylated bi- to tetraantennary complex-type N-glycans with or without a core fucose. To investigate how these glycans enhance the ability of sICAM-1 to induce MIP-2 production, we compared the functional properties of sICAM-1-CT with those of sICAM-1 containing only high mannose-type N-glycans (sICAM-1-HM), which displays only weak MIP-2-inducing activity [24]. Unexpectedly, both sICAM-1-CT and sICAM1-HM bound with similar nanomolar affinities to mouse astrocytes. However, the MIP-2-inducing effect of sICAM1-CT was more rapid, more pronounced, and more prolonged. Analysis by laser scanning microscopy showed that sICAM-1-CT accumulated at the astrocytic plasma membranes within 30 min whereas sICAM-1-HM remained diffusely distributed.

\section{MATERIALS AND METHODS}

\section{Materials}

Peptide N-glycosidase F (PNGase F) was from Roche, Basel, Switzerland. The $\alpha 2,3$-linkage-specific sialidase was the Salmonella typhimurium LT2 sialidase expressed in $E$. coli from Takara Bio Inc., Otsu, Japan (stock at $50 \mathrm{U} / \mathrm{ml}$ ). Recombinant Arthrobacter ureafaciens sialidase expressed in E. coli (stock at $5 \mathrm{U} / \mathrm{ml}$ ), Diplococcus pneumoniae $\beta 1,4-$ galactosidase (stock at $1 \mathrm{U} / \mathrm{ml}$ ), bovine epididymis $\alpha$ fucosidase (stock at $0.5 \mathrm{U} / \mathrm{ml}$ ), almond meal $\alpha 1,3 / 4$-specific fucosidase (stock at $0.5 \mathrm{mU} / \mathrm{ml}$ ), and jack bean $\beta-\mathrm{N}$ acetylhexosaminidase (stock at $30 \mathrm{U} / \mathrm{ml}$ ) were all from Prozyme, San Leandro, CA. Dulbecco's modified Eagle's medium (DMEM), trypsin-EDTA, gentamycin, and sterile phosphate buffered saline (PBS) were bought from Invitrogen, Basel, Switzerland. Fetal bovine serum (FBS) was from BioConcept, Allschwil, Switzerland, and poly-L-lysine, human $\alpha-1$ acid glycoprotein (AGP), bovine serum albumin (BSA), dibutylphthalate, and mineral oil were from Sigma. Iodobeads ${ }^{\circledR}$ were purchased from Pierce, Rockford, IL. Sodium $\left[{ }^{125} \mathrm{I}\right]$ iodide was obtained from GE Healthcare, Uppsala, Sweden. Biotinylated anti-mouse ICAM-1 antibody was from R\&D Systems, Abingdon, UK. Streptavidin-Cy3 conjugate was bought from Sigma and Alexa Fluor ${ }^{\circledR} 660$ phalloidin from Invitrogen. 4',6-Diamidine-2-phenylindole dihydrochloride (DAPI) was obtained from Roche.

\section{Expression, Purification, and Quantification of Mouse SICAM-1}

The extracellular portion of mouse sICAM-1 with the 12 amino acid HPC4 epitope tag attached to its C-terminus after G441 was expressed in CHO cells (sICAM-1-CT) or in Lec1 cells (sICAM-1-HM) and affinity-purified from culture supernatants as described [24]. Concentrations of purified sICAM-1 were assessed by enzyme-linked immunosorbent assay (standard curve, 0-20 ng/ml; lower detection limit, 57 $\mathrm{pg} / \mathrm{ml}$; R\&D Systems). Conversion from $\mathrm{ng} / \mathrm{ml}$ into $\mathrm{nM}$ was performed using a standard of concentrated sICAM-1-CT with known concentration as determined by absorbance at $280 \mathrm{~nm}$ [24].

\section{Profiling and Sequencing of N-Glycans}

The N-glycans of $1 \mathrm{nmol}$ sICAM-1-CT were enzymatically released, derivatized with 8-aminopyrene-1,3,6- trisulfonic acid (APTS), and treated with single or combined exoglycosidases as described [28] except that the exoglycosidase digestions were performed in a total volume of $2 \mu \mathrm{l}$ : $0.4 \mu \mathrm{l}$ sample, $0.2 \mu \mathrm{l}$ of each enzyme preparation, $0.1 \mu \mathrm{l}$ of $100 \mathrm{mM}$ ammonium acetate and water up to $2 \mu \mathrm{l}$. The digestions were incubated overnight at $37^{\circ} \mathrm{C}$ in $250 \mu 1$ PCR tubes, diluted 20-fold in deionized water and analyzed on an ABI 3130 4-capillary DNA sequencer (Applied Biosystems, Foster City, CA) in an instrument-specific implementation of the previously reported method [28]. Briefly, the Applied Biosystems POP7 separation polymer was used as provided by the supplier, as was the separation buffer optimized for DNA separations. Sample injection into the capillaries was achieved electrokinetically at $15 \mathrm{kV}$ for $16 \mathrm{~s}$, followed by separation for $20 \mathrm{~min}$ at $15 \mathrm{kV}$. The samples were spiked with a LIZ-labeled DNA fragment internal standard (Applied Biosystems) prior to analysis, and the electropherograms were corrected for small run-to-run variations based on the localization of the internal standard peaks. This procedure yields a SD for the peak migration of $<0.05$ Glucose Units.

\section{Preparation of Primary Mouse Astrocyte Cultures}

Astrocytes were isolated from the brains of newborn C57BL/6 mice and cultured as described [9,29].

\section{Preparation of $\left[{ }^{125} \mathrm{I}\right] \mathrm{SICAM}-1$}

One Iodobead ${ }^{\circledR}$ was incubated with $150 \mu \mathrm{Ci}$ sodium $\left[{ }^{125} \mathrm{I}\right]$ iodide in $25 \mu \mathrm{l}$ TBS $(20 \mathrm{mM}$ Tris- $\mathrm{HCl}, 150 \mathrm{mM} \mathrm{NaCl}, \mathrm{pH}$ 7.4) for $5 \mathrm{~min}$. Subsequently, $500 \mu \mathrm{l}$ sCAM-1 in TBS (corresponding to $\sim 140$ pmol sICAM-1-CT and to $\sim 415$ pmol sICAM-1-HM) were added for $12 \mathrm{~min}$. [ $\left.{ }^{125} \mathrm{I}\right] \mathrm{sICAM}-1$ was separated from unreacted free $\left[{ }^{125} \mathrm{I}\right]$ iodide on a Sephadex G25 column (PD-10, GE Healthcare) by elution with TBS. Fractions containing $\left[{ }^{125} \mathrm{I}\right] \mathrm{sICAM}-1$ were identified using a $\gamma$-counter (Packard Cobra Gamma Counter B 5002, Perkin Elmer, Wellesley, MA), pooled, supplemented with $1 \%$ $(\mathrm{w} / \mathrm{v}) \mathrm{BSA}$, and filtered through a $0.22 \mu \mathrm{m}$ low proteinbinding filter. $\left[{ }^{125} \mathrm{I}\right] \mathrm{sICAM}-1$ was quantified by enzymelinked immunosorbent assay and stored at $4{ }^{\circ} \mathrm{C}$ until use. The specific activity was between 58 to $128 \mathrm{Ci} / \mathrm{mmol}$ for $\left[{ }^{125} \mathrm{I}\right] \mathrm{sICAM}-1-\mathrm{CT}$ and about $17 \mathrm{Ci} / \mathrm{mmol}$ for $\left[{ }^{125} \mathrm{I}\right] \mathrm{sICAM}-1$ HM.

\section{sICAM-1 Mixed-Type Saturation/Inhibition Binding As- say}

Primary mouse astrocytes were split 1:2 and grown to confluency in poly-L-lysine-coated cell culture flasks. Sixteen hours before performing the assay, the cell culture medium was replaced by binding media (DMEM containing $1 \%$ FBS and $0.05 \%$ gentamycin). The cells were then washed three times with PBS, trypsinized, centrifuged (180 x g, 4 ${ }^{\circ} \mathrm{C}, 10 \mathrm{~min}$ ), and resuspended in $2 \mathrm{ml}$ binding media using a fire-treated Pasteur pipette. Another $8 \mathrm{ml}$ binding media was added to the cell suspension, and astrocytes were allowed to recover for $1 \mathrm{~h}$ at $37^{\circ} \mathrm{C}$ with gentle shaking (180 rpm). Aliquots of $1 \times 10^{5}$ cells were pelleted in $0.5 \mathrm{ml}$ polypropylene tubes $(400 \mathrm{x} \mathrm{g}$, room temperature (RT), $10 \mathrm{~min}$ ) and put on ice. The cells were resuspended in $25 \mu 1$ prechilled binding media containing both increasing concentrations of $\left[{ }^{125} \mathrm{I}\right] \mathrm{sICAM}-1\left(0 \mathrm{nM}\right.$ to $63 \mathrm{nM}$ of $\left[{ }^{125} \mathrm{I}\right] \mathrm{sICAM}-1-\mathrm{CT}$; $0 \mathrm{nM}$ to $200 \mathrm{nM}$ of $\left.\left[{ }^{125} \mathrm{I}\right] \mathrm{sICAM}-1-\mathrm{HM}\right)$ and increasing concentrations of competing unlabeled sICAM-1 ( $0 \mathrm{nM}$ to $250 \mathrm{nM}$ of 
sICAM-1-CT; $0 \mathrm{nM}$ to $500 \mathrm{nM}$ of sICAM-1-HM) and incubated on ice for $2 \mathrm{~h}$. In control experiments, cells were incubated with $25 \mathrm{nM}\left[{ }^{125} \mathrm{I}\right] \mathrm{sICAM}-1-\mathrm{CT}$ and increasing concentrations of unlabeled AGP $(0 \mathrm{nM}$ to $1000 \mathrm{nM})$. The cells were centrifuged (16,100 x g, RT, $2 \mathrm{~min})$ through $100 \mu \mathrm{l}$ of a mixture of dibutylphthalate and mineral oil $(9: 1 \mathrm{v} / \mathrm{v} ; \rho=1.02$ $\mathrm{g} / \mathrm{ml}$ ). The supernatant aqueous phase with unbound radioligand and most of the oil phase were removed and the tube tip containing the cell pellet was cut. The cell-bound radioactivity contained in the tube tip was counted in a $\gamma$-counter.

\section{Analysis of $\left[{ }^{125} \mathrm{I}\right] \mathrm{sICAM}-1$ Binding Data}

All nonlinear regression analyses were performed using the Prism software (Version 4.0, GraphPad ${ }^{\circledR}$, San Diego, CA). The collected data sets were subjected to a global nonlinear regression analysis based on the following equation using two independent variables, the concentrations of the radioligand $\mathrm{L}$ ([ $\left.\left.{ }^{125} \mathrm{I}\right] \mathrm{sICAM}-1\right)$ and of the inhibitor I (sICAM-1).

$$
\mathrm{B}=\frac{\mathrm{B}_{\max } *[\mathrm{~L}]^{\mathrm{n}}}{\mathrm{K}_{\mathrm{d}}{ }^{\mathrm{n}} *\left(1+\frac{[\mathrm{I}]}{\mathrm{K}_{\mathrm{i}}}\right)+[\mathrm{L}]^{\mathrm{n}}}+\mathrm{K}_{\mathrm{nsb}} *[\mathrm{~L}]
$$

$\mathrm{B}$ indicates total $\left[{ }^{125} \mathrm{I}\right] \mathrm{sICAM}-1$ binding, $\mathrm{B}_{\max }$ is the total receptor number detected by $\left[{ }^{125} \mathrm{I}\right] \mathrm{sICAM}-1 . \mathrm{K}_{\mathrm{d}}$ denotes the equilibrium dissociation constant for the binding of the radioligand $\mathrm{L} ; \mathrm{K}_{\mathrm{i}}$ is the equilibrium inhibition constant for the binding of the inhibitor I, with [L] and [I] being the concentrations of the radioligand and inhibitor, respectively. The constant $\mathrm{K}_{\mathrm{nsb}}$ was implemented into the equation to estimate the extent of nonspecific radioligand binding and the slope factor $n$ to test for a deviation of the $\left[{ }^{125}\right.$ I] SICAM-1/sICAM-1 interaction from normal mass action behavior. In all analyses the parameters $\mathrm{K}_{\mathrm{d}}, \mathrm{K}_{\mathrm{i}}, \mathrm{B}_{\max }, \mathrm{n}$, and $\mathrm{K}_{\mathrm{nsb}}$ were treated as shared parameters. First, it was tested with $\mathrm{n}$ fixed to 1 whether $\mathrm{K}_{\mathrm{nsb}}$ was significantly different from zero by statistically comparing the global fits obtained by nonlinear regression analysis, using a partial F-test. This was not the case $(\mathrm{P}>0.05)$. Second, we tested whether the slope factors of the curves were different from unity (unity corresponding to $\mathrm{n}=$ 1 ), which was not the case either. Therefore, $K_{d}, K_{i}$, and $B_{\max }$ were determined as best fit values from global regression analyses of the binding data with $\mathrm{K}_{\mathrm{nsb}}$ and $\mathrm{n}$ fixed to 0 and 1 , respectively.

\section{Native PAGE Analysis of SICAM-1}

Aliquots of sICAM-1-CT and sICAM-1-HM (at $40 \mathrm{nM}$ and $400 \mathrm{nM}$ ) were analyzed by polyacrylamide gel electrophoresis in 5\%,6\%,7\%, and $8 \%$ gels and a Tris-Glycine running buffer at $\mathrm{pH} 8.3$ under native conditions (i.e. without SDS or reducing agents). The monomer $(66 \mathrm{kDa})$ and dimer $(132 \mathrm{kDa})$ of BSA and the trimer $(272 \mathrm{kDa})$ and hexamer (545 kDa) of jack bean urease (both from Sigma) were used as the protein standards following the manufacturer's recommendations. Bromophenol blue served as tracking dye. After electrophoresis, the gel was divided into two parts, one containing the separated standard proteins and the other one the separated sICAM-1 samples. The standard proteins were visualized by either Coomassie Blue staining [30] or silver staining [31]. Urease was visualized by a previously described urease-specific staining method [32]. sICAM-1 bands were visualized by Western blot using an antibody directed against the C-terminal HPC4 epitope tag of sICAM1 as previously described [24]. The relative mobility $\left(R_{f}\right)$ of all bands in all four gel concentrations was determined and $\log \mathrm{R}_{\mathrm{f}}$ values were plotted versus gel concentrations according to [33]. Slopes of the curves obtained for the standard proteins and sICAM-1 were calculated by linear regression analysis. Slopes of the standard protein curves were plotted against the standard protein molecular weights in a log-log graph using the method described by Bryan [34]. This loglog standard curve was used to calculate the molecular weights of sICAM-1-CT and SICAM-1-HM.

\section{Kinetics of MIP-2 Production in Astrocytes in the Pres- ence and after Removal of the Inducing SICAM-1}

Two experimental formats were used. (i) Sixteen hours after replacing the culture medium with medium containing $1 \%$ FBS, mouse astrocytes were treated with $37 \mathrm{nM}$ sICAM1 in medium with $1 \%$ FBS for increasing time periods $(0,7$, $60,120,240,480$, or $1440 \mathrm{~min})$, the cell supernatants were harvested (SN I), the cells washed three times with PBS and fed with fresh medium (1\% FBS). After $24 \mathrm{~h}$, these second supernatants were harvested as well (SN II). (ii) Sixteen hours after replacing the culture medium with medium containing 1\% FBS, mouse astrocytes were treated with $37 \mathrm{nM}$ sICAM-1 for $1 \mathrm{~h}$, washed three times with PBS and fed with fresh medium. Then, the cell culture supernatants were harvested at different time points $(7,60,120,240,480$, or 1440 min). All collected supernatants were immediately centrifuged to remove cellular debris $\left(400 \mathrm{x} \mathrm{g}, 4{ }^{\circ} \mathrm{C}, 10 \mathrm{~min}\right)$ and stored at $-20{ }^{\circ} \mathrm{C}$ until analysis. Mouse MIP-2 was quantified by enzyme-linked immunosorbent assay (standard curve 0 $500 \mathrm{pg} / \mathrm{ml}$; lower detection limit $1.5 \mathrm{pg} / \mathrm{ml}$; no nonspecific signals from mouse sICAM-1; R\&D Systems).

\section{Statistical Analysis of MIP-2 Release Kinetics after 1 h Stimulation with SICAM-1}

Experimental data were fitted individually to the following monoexponential function:

$$
\mathrm{Y}=\mathrm{Y}_{\max } *\left(1-\mathrm{e}^{\left(\mathrm{k}_{\mathrm{obs}} * \mathrm{t}\right)}\right)
$$

This function starts at zero and ascends to $Y_{\max }$ with a rate constant $\mathrm{k}_{\mathrm{obs}}$. The half time is $0.69 / \mathrm{k}_{\mathrm{obs}}$. Bi-exponential curve fitting did not yield better results (F-test, $\mathrm{P}>0.05$, data not shown). A two-tailed Student's T-test was performed to compare the observed rate constants $\mathrm{k}_{\mathrm{obs}}$ of MIP-2 induction using the Instat software (Version 3.0, $\mathrm{GraphPad}^{\circledR}$, San Diego, CA).

\section{Visualization of sICAM-1 on Astrocytes by Confocal La- ser Scanning Microscopy}

Confluent cultures of primary mouse astrocytes were trypsinized, plated in poly-L-lysine-coated cell culture inserts for 6-well plates (BD Biosciences, $0.4 \mu \mathrm{m}$ transparent PET membrane, $5 \times 10^{5}$ cells/insert) and cultured for another 10 days in DMEM containing $10 \%$ FBS and $0.05 \%$ gentamycin. Sixteen hours before stimulation, the culture medium was replaced with medium containing 1\% FBS. Astrocytes were incubated either with $500 \mathrm{nM}$ sICAM-1-CT, 500 nM sICAM-1-HM (concentrations corresponding to 1.7 fold $\mathrm{K}_{\mathrm{i}}$ ), or with vehicle controls for $30 \mathrm{~min}$ at $37{ }^{\circ} \mathrm{C}$. The cells 
were rinsed three times with ice-cold PBS and fixed with $3 \%$ $(\mathrm{w} / \mathrm{v})$ paraformaldehyde in PBS for $15 \mathrm{~min}$. The cellcarrying membranes were excised from the inserts, washed, and incubated in $0.1 \mathrm{M}$ glycine in PBS overnight at $4{ }^{\circ} \mathrm{C}$. The cells were then washed and permeabilized by incubation with $0.2 \%(\mathrm{v} / \mathrm{v})$ Triton X-100 in PBS for $15 \mathrm{~min}$. After washing, the cells were blocked with medium containing $10 \%$ FBS for $20 \mathrm{~min}$ and washed again. To block endogenous streptavidin-binding sites, the cells were treated with streptavidin solution for $15 \mathrm{~min}$ at room temperature followed by incubation with biotin solution for $15 \mathrm{~min}$ at room temperature (Streptavidin/Biotin Blocking Kit, Vector Laboratories, Burlingame, $\mathrm{CA})$. The cells were washed and then incubated with a biotinylated anti-ICAM-1 antibody (15 $\mu \mathrm{g} / \mathrm{ml}$ in $3 \% \mathrm{BSA}$ in PBS) for $1 \mathrm{~h}$ at $37{ }^{\circ} \mathrm{C}$ in a humid chamber. After extensive washing, the cells were incubated with a mixture of streptavidin-Cy3 (1:500), DAPI $(1 \mu \mathrm{g} / \mathrm{ml})$, and Alexa Fluor ${ }^{\circledR} 660$ phalloidin (1:10) in 3\% BSA/PBS for 90 min at $37{ }^{\circ} \mathrm{C}$ in a humid chamber. Due to endogenous ICAM-1 expression by astrocytes, vehicle control cells stained omitting the biotinylated anti-ICAM-1 antibody were used as negative controls. After washing three times in TBS, membranes were mounted in Lisbeth's embedding medium (70\% (v/v) glycerol, $30 \mathrm{mM}$ Tris- $\mathrm{HCl} \mathrm{pH} 9.5,5 \%(\mathrm{w} / \mathrm{v}) \mathrm{n}-$ propylgallate) and stored in the dark at $4{ }^{\circ} \mathrm{C}$. Fluorescence was visualized with a Zeiss LSM 510 inverted microscope with a C-Apochromat $63 \mathrm{x} / 1.20 \mathrm{~W}$ lens using HeNe $543 \mathrm{~nm}$ and diode $405 \mathrm{~nm}$ lasers. The amplification of the $\mathrm{Cy} 3$ channel was set to exclude the background signal in the negative controls and kept constant throughout the experiment. Threedimensional multichannel image processing was performed using IMARIS software (Bitplane AG, Zurich, Switzerland).

\section{RESULTS}

The N-Glycans of Mouse sICAM-1-CT are Mostly $\alpha 2,3-$ Sialylated, Core-Fucosylated Bi- to Tetraantennary Complex-Type N-Glycans and Include a Small Fraction of Non-Fucosylated Bi- and Triantennary N-Glycans Carrying Sialic Acid in Linkages other than $\alpha 2,3$

In a previous study we found that sialylated and galactosylated complex-type $\mathrm{N}$-glycans as synthesized by CHO cells strongly enhance the ability of mouse sICAM-1 to induce MIP-2 production in astrocytes [24]. A second study based on MALDI-TOF mass spectrometry showed that the sialylated and galactosylated $\mathrm{N}$-glycans of mouse sICAM-1 from CHO cells (sICAM-1-CT) were mostly diand trisialylated complex-type $\mathrm{N}$-glycans with or without one fucose; altogether 61 different $\mathrm{N}$-glycan species were observed by MALDI-TOF mass spectrometry. About $4 \%$ of the sialylated $\mathrm{N}$-glycans carried a higher number of sialic acid residues than of antennae [35]. Here, we aimed at better defining the structures of the function-enhancing sialylated complex-type N-glycans of sICAM-1-CT. For this purpose, $\mathrm{N}$-glycans were enzymatically released, fluorescently labeled, treated with single or combined exoglycosidases, and analyzed by electrophoresis in a DNA sequencer [28]. Virtually all peaks in the electropherogram of the untreated $\mathrm{N}$-glycans shifted after treatment with a sialidase of broad linkage specificity (panels $\mathbf{b}$ and $\mathbf{c}$ in Fig. 1A), showing that more than $90 \%$ of the $\mathrm{N}$-glycans were sialylated. When analyzed after treatment with a sialidase that is specific for a2,3-linked sialic acid (panel $\mathbf{d}$ in Fig. 1A), the heights of peaks 3', 4', and 4', were reduced and three new peaks (3's, were reduced and three new peaks (3's, 4's, 4's) appeared, compared to the electropherogram obtained after treatment with the sialidase of broad linkage specificity. This observation suggests that three glycan species corresponding to $\sim 5 \%$ of the total sialylated N-glycans in sICAM-1-CT contain sialic acid in linkages other than $\alpha 2,3$. It is possible that these represent $\alpha 2,8$-linked sialic acids, since $\mathrm{CHO}$ cells can generate polysialic acids with $\alpha 2,8$ linkages, but lack sialic acid in $\alpha 2,6$ linkage.

Comparison of the electropherograms after treatment with various combinations of exoglycosidases (sialidase, galactosidase, fucosidase, $\mathrm{N}$-acetylhexosaminidase) showed that essentially all N-glycans of sICAM-1-CT - with the exception of a small fraction $(\sim 5 \%)$ of high mannose-type $\mathrm{N}$ glycans (Fig. 1, peak 2) - were of the complex-type. The most abundant complex-type $\mathrm{N}$-glycans were monofucosylated biantennary ( $\sim 17 \%$ according to peak height), nonfucosylated triantennary $(\sim 28 \%)$, and monofucosylated tetraantennary ( $26 \%$; Figs. 1A, B, panels c, bold letters). Lower amounts of non-fucosylated biantennary $(\sim 7 \%)$, monofucosylated triantennary $(\sim 12 \%)$, non-fucosylated tetraantennary $(\sim 3 \%)$, and monofucosylated tetraantennary $\mathrm{N}$-glycans with a lactosamine repeat $(\sim 1.7 \%)$ were present as well. Sialic acid in linkages resistant to digestion with $\alpha 2,3$ specific sialidase was found on non-fucosylated biantennary and on the two non-fucosylated triantennary $\mathrm{N}$-glycan isomers (Figs. 1A, B, panels d).

Virtually no differences were detected between the electropherograms of sICAM-1-CT N-glycans treated with either sialidase and an $\alpha 1,3 / 4$-specific fucosidase or with sialidase alone (Fig. 1A, panels $\mathbf{g}$ and $\mathbf{c}$ ). In contrast, the positions of several peaks (3'f, 4'f, 4''f, 5'f, 6'f) differed between the electropherograms of sICAM-1-CT N-glycans treated with either sialidase and a fucosidase with broad linkage specificity or sialidase alone (Fig. 1A , panels $\mathbf{f}$ and $\mathbf{c}$ ). In N-glycans, fucose occurs either in $\alpha 1,3 / 4$-linkage to $\mathrm{N}$-acetylglucosamine residues in the antennae or in $\alpha 1,6$-linkage to the first $\mathrm{N}$-acetylglucosamine of the core. The present results show that all fucoses found on N-glycans of mouse sICAM-1-CT are $\alpha 1,6$-linked to the core.

Taken together, the N-glycans enhancing the MIP-2inducing activity of sICAM-1-CT were sialylated bi- to tetraantennary complex-type $\mathrm{N}$-glycans with or without a core fucose with a small fraction of non-fucosylated bi- and triantennary $\mathrm{N}$-glycans carrying sialic acid in linkages other than $\alpha 2,3$.

\section{sICAM-1-CT and SICAM-1-HM Bind to Astrocytes with Similar Affinities}

To explore the underlying mechanisms of the enhanced MIP-2-inducing capacity of SICAM-1-CT in mouse astrocytes, we tested whether sICAM-1-CT may bind to astrocytes with higher affinity compared to sICAM-1-HM. sICAM-1-HM derived from the Lec1 mutant of CHO cells [36,37] exclusively carries high mannose-type $\mathrm{N}$-glycans of the composition $\mathrm{Man}_{5} \mathrm{GlcNAc}_{2}$ and displays only weak MIP2 -inducing activity in mouse astrocytes [24,35]. The binding of ${ }^{125}$ I-labeled sICAM-1 ([ $\left.{ }^{125} \mathrm{I}\right]$ sICAM-1) and unlabeled sICAM-1 to astrocytes was analyzed in mixed-type saturation/inhibition binding experiments, similar to the procedure proposed by Rovati [38], to obtain estimates for the equilib- 


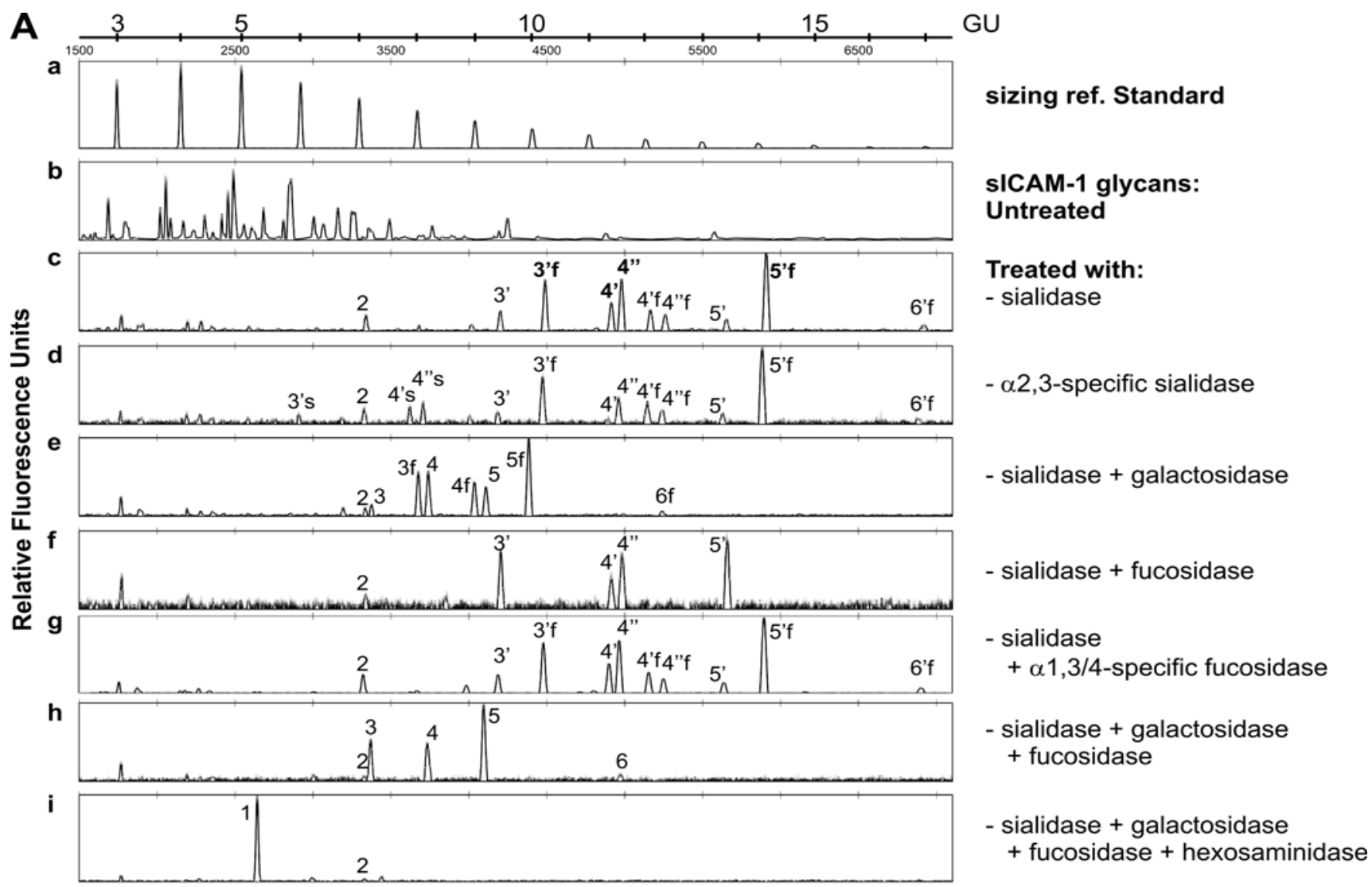

B
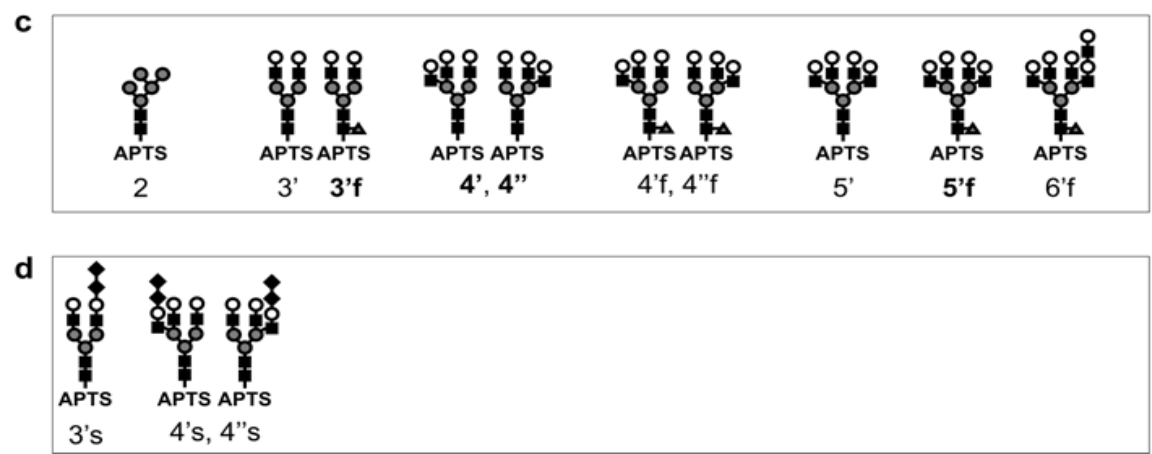

Fig. (1). Characterization and structural analysis of the N-glycans present on mouse sICAM-1 expressed in CHO cells (sICAM-1-CT). A, Nglycans were enzymatically released from 1 nmol of mouse sICAM-1-CT, labeled with 8-aminopyrene-1,3,6-trisulfonic acid (APTS), treated with an array of single and combined exoglycosidases, and analyzed by electrophoresis on a DNA sequencer. As a reference for glycan sizes, the malto-oligosaccharide sizing reference standard was used and the relevant size range of 3 to 17 glucose units (GU) is shown (panel a). Panels $b-i$ : Electrophoretic profiles obtained before (panel $b$ ) and after digestion of sICAM-1 N-glycans with single or combined exoglycosidases (panels $c$-i). Sialidase designates a sialidase with broad linkage specificity and fucosidase a fucosidase with broad linkage specificity. The observed peaks could be assigned to the following glycans: peak Nr. 1: $\mathrm{Man}_{3} \mathrm{GlcNAc}_{2}$, peak Nr. 2: Man ${ }_{5} \mathrm{GlcNAc}{ }_{2}$, peak Nr. 3: $\mathrm{GlcNAc}_{2} \mathrm{Man}_{3} \mathrm{GlcNAc}_{2}$, peak Nr. 4: GlcNAc $\mathrm{Man}_{3} \mathrm{GlcNAc}_{2}$, peak Nr. 5: GlcNAc $\mathrm{Man}_{3} \mathrm{GlcNAc}_{2}$, peak Nr. 6: (GlcNAcGal) GlcNAc $_{4} \mathrm{Man}_{3} \mathrm{GlcNAc}_{2}$. The galactosylated forms of the glycans contained in peaks 3, 4, 5 are designated 3', 4', 4', 5' (panel f), with 4' and 4' representing isomers with the third antenna attached to either the Man $\alpha 1,3$ or the Man $\alpha 1,6$ arm of the trimannosyl core. Peaks containing fucosylated glycans are indicated by an $\mathrm{f}$ and presence of sialic acid resistant to $\alpha 2,3$-specific sialidase by s. The profiles result from one out of 2 experiments which gave identical results. B, Structures of the N-glycans attributed to the main peaks in panels $c$ and $d$. The most abundant $\mathrm{N}$-glycans (as judged from the peak heights) are highlighted by bold letters. The component monosaccharides are represented by the symbols proposed by the nomenclature committee of the Consortium for Functional Glycomics (http://glycomics.scripps.edu/ CFGnomenclature.pdf):

G GlcNAc; $\bigcirc \mathrm{Man} ; \triangle$ Fuc $\bigcirc \mathrm{Gal} ;>$ NeuAc. 
A

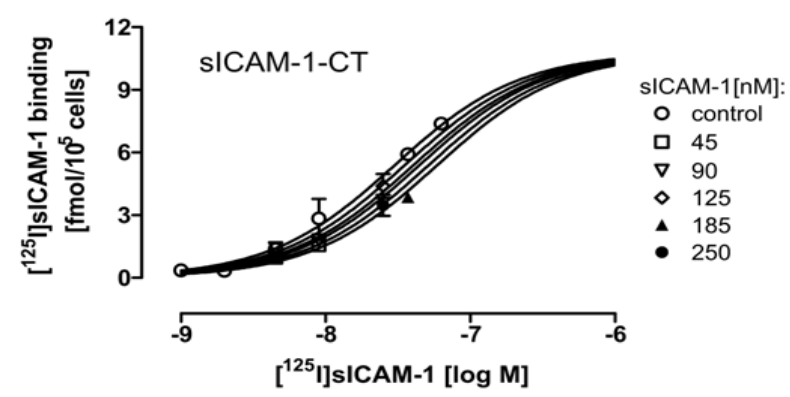

B

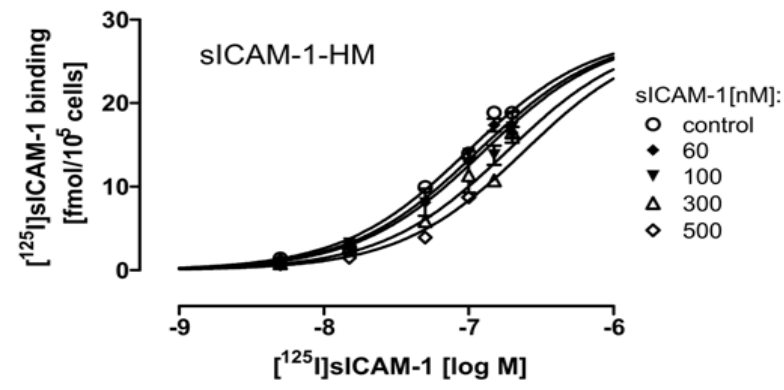

C

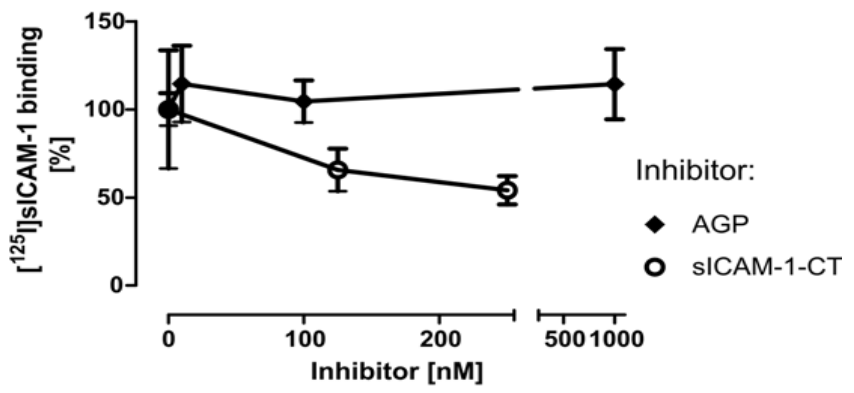

D

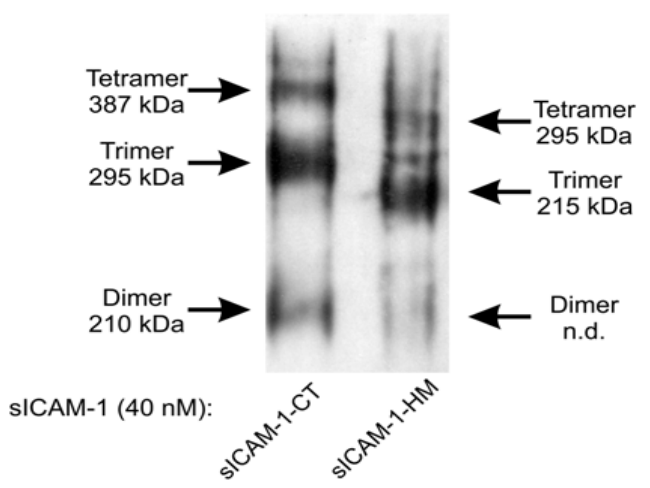

Fig. (2). sICAM-1-CT and sICAM-1-HM bind to astrocytes with similar affinities. Primary mouse astrocytes were incubated with increasing concentrations of either $\left[{ }^{125} \mathrm{I}\right] \mathrm{sICAM}-1-\mathrm{CT}$ and competing unlabeled sICAM-1-CT (A) or [ $\left.{ }^{125} \mathrm{I}\right] \mathrm{sICAM}-1-\mathrm{HM}$ and competing unlabeled sICAM-1-HM (B) for $2 \mathrm{~h}$ on ice, and cell-bound $\left[{ }^{125} \mathrm{I}\right] \mathrm{sICAM}-1$ was determined. The results are presented as average \pm SEM of one representative experiment out of four (A) or two (B), each performed in duplicate. Error bars are only shown when they exceed the size of the symbols. Curve fitting was performed globally subjecting the collected data to a nonlinear regression analysis as described in Materials and Methods. (C) Astrocytes were incubated with $25 \mathrm{nM}\left[{ }^{125} \mathrm{I}\right] \mathrm{sICAM}-1-\mathrm{CT}$ and various concentrations of competing unlabeled sICAM-1-CT (open circles, $\mathrm{n}=3$, each performed in duplicate) or human AGP (diamonds, $\mathrm{n}=2$, each performed in duplicate) for $2 \mathrm{~h}$ on ice, and cell-bound $\left[{ }^{125} \mathrm{I}\right] \mathrm{sICAM}-1-\mathrm{CT}$ was measured. The results were normalized to $\left[{ }^{125} \mathrm{I}\right] \mathrm{sICAM}-1-\mathrm{CT}$ binding in the absence of competitor, which was set to $100 \%$. Data are shown as average \pm SD. (D) Aliquots of sICAM-1-CT and sICAM-1-HM (40 nM, 400 nM) were subjected to native PAGE using various gels differing in acrylamide concentrations $(5 \%, 6 \%, 7 \%, 8 \%)$ and a Tris-Glycine (pH 8.3) running buffer. sICAM-1 was detected by Western blotting and staining with HPC4 antibody. Monomeric and dimeric BSA and trimeric and hexameric urease were used as standard proteins to calculate the molecular weights of sICAM-1 oligomers. One representative experiment is shown, in which aliquots of 40 $\mathrm{nM}$ protein solutions were analyzed in an $8 \%$ gel. sICAM-1 oligomers are indicated by arrows with molecular masses calculated as described in Materials and Methods. Due to the diffuseness of the band, the molecular mass of the sICAM-1-HM dimer could not be determined (n.d.).

rium dissociation constant $\mathrm{K}_{\mathrm{d}}$ of $\left[{ }^{125} \mathrm{I}\right] \mathrm{sICAM}-1$ and the equilibrium inhibition constant $\mathrm{K}_{\mathrm{i}}$ of competing unlabeled sICAM-1 for both sICAM-1-CT and sICAM-1-HM. $\left[{ }^{125} \mathrm{I}\right] \mathrm{sICAM}-1$ binding was studied for sICAM-1-CT and sICAM-1-HM at increasing but non-saturating concentrations in the absence and presence of low to intermediate concentrations of unlabeled sICAM-1. Graphically, this yielded a set of binding isotherms of $\left[{ }^{125}\right.$ I] sICAM-1 (Figs. 2A, B). Global nonlinear regression analysis of the data sets obtained for sICAM-1-CT versus sICAM-1-HM revealed a competitive interaction between $\left[{ }^{125} \mathrm{I}\right] \mathrm{sICAM}-1$ and unlabeled sICAM-1. The binding parameters characterizing the interaction of sICAM-1-CT and sICAM-1-HM with astrocytes are summarized in Table 1. Since iodination alters the molecular entity of a protein, we used the binding affinities of the unlabeled competing sICAM-1 rather than the binding affinities of the $\left[{ }^{125} \mathrm{I}\right] \mathrm{sICAM}-1$ for comparison between sICAM-1-CT and sICAM-1-HM. Unlabeled sICAM-1-CT bound to astrocytes with $\mathrm{pK}_{\mathrm{i}}=6.50$ (corresponding to a $\mathrm{K}_{\mathrm{i}}$ of roughly 300 $\mathrm{nM}$ ). Binding of unlabeled sICAM-1-HM to astrocytes occurred with $\mathrm{pK}_{\mathrm{i}}=6.48$. The difference in binding affinities of the unlabeled sICAM-1-CT and sICAM-1-HM to astro- cytes did not reach statistical significance (T-test, $\mathrm{P}=$ 0.7989). Therefore, sICAM-1-CT and sICAM-1-HM bind to astrocytes with similar affinities. Interestingly, a significantly different number of binding sites was obtained for $\left[{ }^{125} \mathrm{I}\right] \mathrm{sICAM}-1-\mathrm{CT} \quad\left(\mathrm{B}_{\max }=73,000 /\right.$ astrocyte $)$ and for $\left[{ }^{125} \mathrm{I}\right] \mathrm{sICAM}-1-\mathrm{HM}\left(\mathrm{B}_{\max }=196,000 /\right.$ astrocyte; T-test, $\mathrm{P}=$ 0.001). The astrocytic mannose receptor [39] seems however not to account for the increased number of binding sites of $\left[{ }^{125} \mathrm{I}\right]$ sICAM-1-HM, since binding was not inhibited by a 100-fold excess of mannan (data not shown). Displacement of $\left.{ }^{125} \mathrm{I}\right] \mathrm{sICAM}-1-\mathrm{CT}$ from astrocyte binding by protein was sICAM-1-specific, as [ $\left.{ }^{125} \mathrm{I}\right]$ sICAM-1-CT binding was inhibited by unlabeled sICAM-1-CT but not by the unrelated glycoprotein human AGP, which contains multiple sialylated complex-type N-glycans (Fig. 2C).

Binding affinities can only be compared if the ligands occur in similar oligomeric states. Therefore, we sought to determine the native oligomeric state for both sICAM-1-CT and sICAM-1-HM. Separation of different oligomeric species of sICAM-1 at protein concentrations relevant for the mixed-type saturation/inhibition binding assay could be 
Table 1. Parameters Characterizing the Binding of ${ }^{125}$ I-labeled and Unlabeled sICAM-1-CT or sICAM-1-HM to Astrocytes

\begin{tabular}{|c|c|c|c|c|c|}
\hline sICAM-1: & $\mathbf{p K}_{\mathbf{d}}{ }^{a}$ & $\mathbf{B}_{\max }{ }^{a}$ & $\mathbf{p K}_{\mathbf{i}}{ }^{b}$ & $\mathbf{n}$ \\
\hline \hline sICAM-1-CT & $7.40 \pm 0.06$ & $73,000 \pm 6,000$ & $6.50 \pm 0.06$ & $0.90 \pm 0.04$ \\
\hline sICAM-1-HM & $6.98 \pm 0.02$ & $196,000 \pm 18,000$ & $6.48 \pm 0.01$ & $1.08 \pm 0.03$ & 4 \\
\hline
\end{tabular}

The abbreviations used are: $\mathrm{pK}_{\mathrm{d}}$ : -log equilibrium dissociation constant of [ $\left.{ }^{125} \mathrm{I}\right] \mathrm{sICAM}-1$ binding to astrocytes; $\mathrm{B}_{\max }$ : maximum number of [ $\left.{ }^{125} \mathrm{I}\right] \mathrm{sICAM}-1$ binding sites/astrocyte. $\mathrm{pK}_{\mathrm{i}}$ : - $\log$ equilibrium inhibition constant of unlabeled sICAM-1 binding to astrocytes. $\mathrm{n}$ : slope factor of the corresponding curve; $\mathrm{pK}$ values were determined by global nonlinear regression analysis of the data sets with $\mathrm{n}$ fixed to 1 . $\mathrm{N}$ : number of independent experiments, each performed in duplicate.

${ }^{a}$ values are significantly different between SICAM-1-CT and sICAM-1-HM (T-test, $\left.\mathrm{P}<0.05\right)$

${ }^{b}$ values do not differ significantly (T-test, $\mathrm{P}>0.05$ ).

The results are presented as average values \pm SEM.

achieved by native PAGE analysis, but not by size exclusion chromatography (not shown). Native PAGE revealed that at $40 \mathrm{nM}$ and $400 \mathrm{nM}$, sICAM-1-CT and sICAM-1-HM were mainly present as trimers with smaller fractions of dimers and tetramers (Fig. 2D). Di-, tri-, and tetramers of sICAM-1CT displayed apparent molecular masses of about $210 \mathrm{kDa}$, $295 \mathrm{kDa}$, and $387 \mathrm{kDa}$, respectively, indicating an apparent molecular mass of the monomer of 96 to $105 \mathrm{kDa}$. Tri- and tetramers of sICAM-1-HM had masses of about $215 \mathrm{kDa}$ and $295 \mathrm{kDa}$, respectively, corresponding to monomeric masses of 72 to $74 \mathrm{kDa}$. Larger sICAM-1 aggregates were neither found by native PAGE nor by size exclusion chromatography (data not shown). These results show that in the concentration range used for the binding assay, sICAM-1-CT and sICAM-1-HM occur in similar oligomeric states ranging from dimeric to tetrameric. The $\mathrm{pK}_{\mathrm{i}}$ values determined for their binding to astrocytes can thus be directly compared.

Taken together, these data show that sICAM-1-CT and sICAM-1-HM do neither differ in oligomeric state nor in their binding affinity to mouse astrocytes. The enhanced capacity of mouse sICAM-1-CT to induce MIP-2 production is therefore not due to an enhanced binding affinity for its astrocytic receptor(s). The data also indicate that there are larger numbers of binding sites for sICAM-1-HM versus sICAM-1-CT on mouse astrocytes.

sICAM-1-CT Induces a more Rapid, Higher Level, and more Prolonged Production of MIP-2 in Astrocytes than SICAM-1-HM

The absence of a difference in binding affinity to mouse astrocytes between sICAM-1-CT and sICAM-1-HM suggested that glycosylation specifically influences the signaling capacity of sICAM-1. The much higher MIP-2 levels observed after a $24 \mathrm{~h}$ treatment of astrocytes with SICAM-1-CT compared to sICAM-1-HM [24] could hence be due to a more prolonged and/or stronger signal delivered to the cell resulting in a more prolonged and/or higher level MIP-2 production.

We first investigated the possibility that the higher levels of MIP-2 produced by primary mouse astrocytes within $24 \mathrm{~h}$ may be due to a more prolonged effect of sICAM-1-CT. Primary mouse astrocytes were treated with either sICAM-1CT or sICAM-1-HM (37 $\mathrm{nM}$ ) for increasing time periods, culture supernatants were harvested (SN I) and replaced by the same volume of fresh media. After 24 more hours the second culture supernatants were harvested as well (SN II) and MIP-2 levels in SN I and SN II were determined.

MIP-2 levels rose steadily up to $24 \mathrm{~h}$ following treatment of astrocytes with sICAM-1-CT (Fig. 3A). A plateau was only reached after $32 \mathrm{~h}$ of continuous stimulation (not shown). In contrast, MIP-2 levels reached a plateau after $8 \mathrm{~h}$ when sICAM-1-HM was used for stimulation (Fig. 3B). At this time point, the MIP-2 levels produced after stimulation with sICAM-1-HM were 60 times lower than after treatment with sICAM-1-CT.

Seven minutes of astrocyte exposure to either sICAM-1CT or sICAM-1-HM was sufficient to induce MIP-2 release in mouse astrocytes in the following $24 \mathrm{~h}$ (Figs. 3C, D). The level of MIP-2 released by mouse astrocytes in the $24 \mathrm{~h}$ period after removal of sICAM-1 depended on the precedent stimulation time. When sICAM-1-CT had been used for stimulation, MIP-2 levels in SN II increased with stimulation time periods of up to $8 \mathrm{~h}$ (Fig. 3C). In contrast, when sICAM-1-HM had been used for stimulation, MIP-2 levels in SN II peaked when the cells had been stimulated for $2 \mathrm{~h}$, but decreased again when they had been stimulated for longer time periods (Fig. 3D). These data show that the effect on MIP-2 production of sICAM-1-CT is both more pronounced and more persistent.

This result led us to investigate whether the MIP-2 response to sICAM-1-CT may, besides being more pronounced and more persistent, also be more rapid than the MIP-2 response to sICAM-1-HM. We therefore treated astrocytes for $1 \mathrm{~h}$ with sICAM-1-CT or sICAM-1-HM (37 $\mathrm{nM}$ ), removed the stimulus, and then measured the MIP-2 levels produced within various time periods. Stimulation with sICAM-1-CT for $1 \mathrm{~h}$ resulted in a half-maximal MIP-2 production at $\mathrm{t}_{1 / 2}=70 \mathrm{~min}$. In contrast, stimulation with sICAM-1-HM induced a half-maximal MIP-2 production at $\mathrm{t}_{1 / 2}=210 \mathrm{~min}$ (Fig. 4). The rate constants for the induction of MIP-2 in primary mouse astrocytes were $\mathrm{k}_{\mathrm{obs}}=0.0099 \pm$ $0.0005 \mathrm{~min}^{-1}$ (average \pm SEM, $\mathrm{n}=3$ ) for sICAM-1-CT and $\mathrm{k}_{\text {obs }}=0.0033 \pm 0.0015 \mathrm{~min}^{-1}(\mathrm{n}=3)$ for sICAM-1-HM (Fig. 4, inset). These values differ significantly (two-tailed T-test, $\mathrm{P}=0.01$ ) and show that the MIP-2 production induced by sICAM-1-CT is more rapid than the MIP-2 production elicited by sICAM-1-HM. Thus, the sialylated complex-type Nglycans on sICAM-1-CT not only lead to a more pronounced and more persistent, but also to a more rapid MIP-2 induction.

\section{sICAM-1 Carrying Sialylated Complex-Type N-Glycans Accumulates at Astrocyte Plasma Membranes}

The equal binding affinity of sICAM-1-CT and SICAM1-HM for astrocytes combined with the more rapid, higher level, and more persistent induction of MIP-2 production by sICAM-1-CT suggested that sICAM-1-CT and sICAM-1HM may be bound with differing kinetics and/or be pro- 
A

SICAM-1-CT: SN I

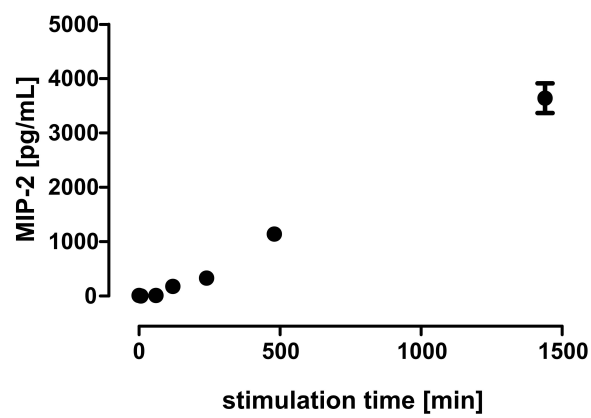

C

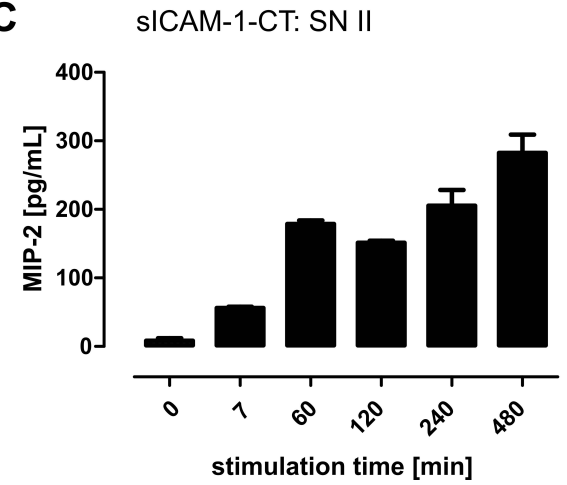

B

SICAM-1-HM: SN I

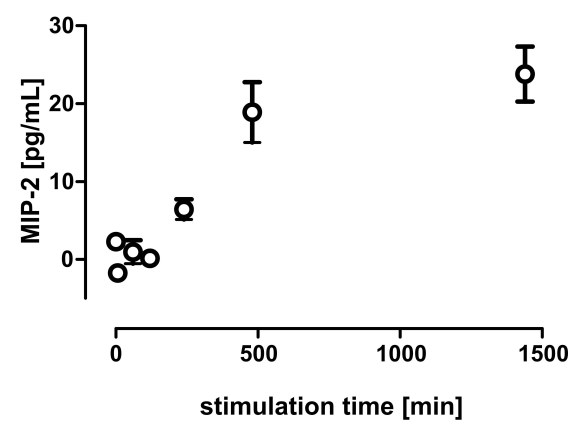

D SICAM-1-HM: SN II

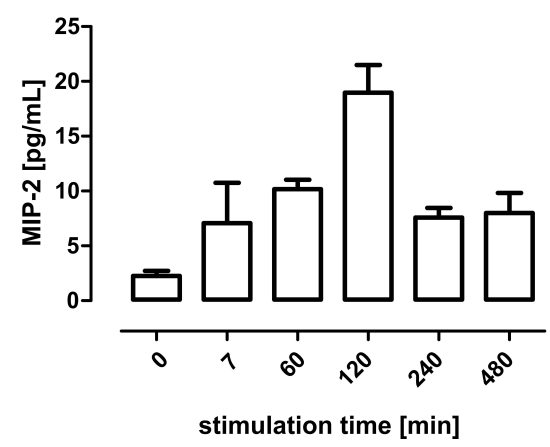

Fig. (3). sICAM-1-CT induces a more pronounced and more prolonged production of MIP-2 in primary mouse astrocytes than sICAM-1-HM. Primary mouse astrocytes were treated with $37 \mathrm{nM}$ of either sICAM-1-CT (A, C) or sICAM-1-HM (B, D) for increasing time periods $(7$ min, $60 \mathrm{~min}, 120 \mathrm{~min}, 240 \mathrm{~min}, 480 \mathrm{~min}, 1440 \mathrm{~min})$. The cell supernatants were harvested $(S N I)$, the cells washed three times with PBS, fed with fresh medium, incubated for 24 more hours, and the second supernatants collected as well (SN II). MIP-2 concentrations in SN I (A, B) and in SN II (C, D) were determined by enzyme-linked immunosorbent assay. The results are presented as average \pm SEM of four assays derived from two independent experiments, each performed in duplicate.

cessed differently by astrocytes. To investigate this hypothesis, mouse astrocytes were incubated with either sICAM-1$\mathrm{CT}$ or sICAM-1-HM for various time periods at $37{ }^{\circ} \mathrm{C}$ and the cellular distribution of sICAM-1 was visualized by immunofluorescence and confocal laser scanning microscopy. Signal amplification for sICAM-1 was set to exclude the background fluorescence detected in negative controls (not shown). After an incubation time of $30 \mathrm{~min}$, sICAM-1-CT had accumulated at astrocyte plasma membranes, as shown by colocalization of sICAM-1 with F-actin staining (Figs. 5A, $\mathbf{A}^{*}$ ), while sICAM-1-HM was diffusely distributed (Figs. 5B, B*). After 120 min incubation time, accumulation of sICAM-1-CT had decreased again (not shown). The distribution of sICAM-1-HM was not altered by co-incubation with a 100-fold excess of mannan suggesting that the lack of cell membrane accumulation was not due to cellular uptake by the mannose receptor (data not shown). These findings show that in contrast to sICAM-1-HM, sICAM-1-CT accumulates at the astrocyte plasma membrane, which correlates with enhanced and prolonged MIP-2 induction by sICAM-1CT.

\section{DISCUSSION}

In previous studies we showed that the ability of mouse sICAM-1 to induce the production of MIP-2 in mouse astrocytes was strongly enhanced when sICAM-1 carried sialylated complex-type $\mathrm{N}$-glycans as synthesized by $\mathrm{CHO}$ cells [24] and that these N-glycans were mostly di- and tri- sialylated with or without one fucose [35]. The present study was aimed at defining the structures of the sialylated $\mathrm{N}$ glycans present on sICAM-1 from $\mathrm{CHO}$ cells and at elucidating mechanisms by which they enhance the ability of sICAM-1 to induce MIP-2 production in astrocytes.

With regard to the structures of the function-enhancing $\mathrm{N}$-glycans on sICAM-1, we found that more than $90 \%$ were sialylated. This result is consistent with previous observations based on isoelectric focusing and sialidase treatment [24] as well as ion-exchange chromatography and MALDITOF mass spectrometry [35]. The sialylated N-glycans were mainly of the core-fucosylated biantennary, non-fucosylated triantennary, and core-fucosylated tetraantennary type. In a separate study, we showed that all nine consensus sequences for N-glycosylation $\left(\mathrm{N}-20\right.$ on the $1^{\text {st }}$ Ig-like domain, N-158 on the $2^{\text {nd }}$ Ig-like domain, N-177, N-240 on the $3^{\text {rd }}$ Ig-like domain, N-284, N-335 on the $4^{\text {th }}$ Ig-like domain, N-361, N$382, \mathrm{~N}-429$ on the $5^{\text {th }}$ Ig-like domain) of mouse sICAM-1 are glycosylated [35]. Hence, the glycan structures defined here may be distributed over all five Ig-like domains of mouse sICAM-1.

Approximately $5 \%$ of the sialylated N-glycans, corresponding to about $50 \%$ of the sialylated, non-fucosylated biand tri-antennary $\mathrm{N}$-glycans, were resistant to $\alpha 2,3$-linkagespecific sialidase. Since $\mathrm{CHO}$ cells lack $\alpha 2,6$ sialyltransferase activity [40] but express the polysialyltransferase ST8SiaIV [41], these sialic acid moieties are most likely 


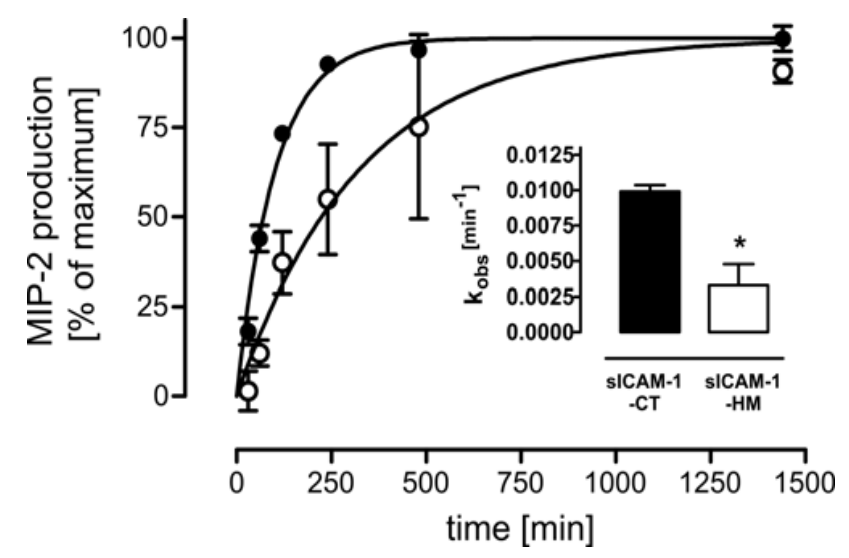

Fig. (4). sICAM-1-CT induces MIP-2 production more rapidly than sICAM-1-HM. Primary mouse astrocytes were treated with 37 nM sICAM-1-CT (filled circles) or sICAM-1-HM (open circles) for $1 \mathrm{~h}$. After washing the cells three times with PBS, fresh cell culture medium was added for the times indicated on the $\mathrm{x}$-axis, and secreted MIP-2 was measured by enzyme-linked immunosorbent assay. Results were normalized to the maximal MIP-2 levels measured, which were set to $100 \%$. When stimulated with sICAM1-CT (inset, black bar), the production of MIP-2 in astrocytes was significantly faster $(* \mathrm{P}<0.05)$ than when stimulated with sICAM1-HM (inset, white bar), as evidenced by the rate constant $\mathrm{k}_{\mathrm{obs}}$. The data are presented as average \pm SEM of six assays derived from three independent experiments, each performed in duplicate.

$\alpha 2,8$-linked. In our previous mass spectrometrical analysis, about $4 \%$ of the sialylated N-glycans of sICAM-1-CT were found to be non-fucosylated $\mathrm{N}$-glycans carrying either three sialic acid residues on maximally two antennae or four sialic acid residues on maximally three antennae [35]. The present finding of sialic acid in linkages other than $\alpha 2,3$ on nonfucosylated bi- and tri-antennary $\mathrm{N}$-glycans combined with the previous finding of a higher number of sialic acid residues than of antennae on these same glycans strongly suggest that sICAM-1-CT contains a small fraction of N-glycans expressing $\alpha 2,8$-linked sialic acids. Whether $\alpha 2,8$-linked sialic acid residues on mouse sICAM-1 are involved in MIP2 induction in astrocytes can not be deduced from the present data. It is unlikely, however, that $\alpha 2,8$-linked sialic acids are the only factor conferring strong MIP-2-inducing activity, since the presence of galactose was found to play a role as well [24].

To elucidate the mechanisms by which sialylated $\mathrm{N}$ glycans enhance the ability of sICAM-1 to induce MIP-2 production in astrocytes, we compared two differentially glycosylated forms of sICAM-1 with either strong or weak MIP-2-inducing activity with respect to their binding affinity to astrocytes. The binding affinities of the two sICAM-1 proteins to the undefined astrocytic sICAM-1 receptor were determined by estimating the $\mathrm{K}_{\mathrm{d}}$ of $\left[{ }^{125} \mathrm{I}\right] \mathrm{sICAM}-1$ binding and the $K_{i}$ with which unlabeled sICAM-1 competed with $\left[{ }^{125} \mathrm{I}\right] \mathrm{sICAM}-1$ for astrocytic binding sites using a mixedtype saturation/competition binding procedure [38]. Instead of determining $\mathrm{K}_{\mathrm{d}}$ by homologous competition experiments, this mixed type protocol combined with a global data analysis allowed us to treat the ${ }^{125}$ I-labeled and the unlabeled sICAM-1 as chemically different ligands. Deviating from the widespread view, the introduction of large polarizable ${ }^{125} \mathrm{I}$ atoms into a protein can lead to altered binding properties as reflected by the difference between the $K_{d}$ of $\left[{ }^{125} \mathrm{I}\right] \mathrm{sICAM}-1$ and the $\mathrm{K}_{\mathrm{i}}$ of unlabeled sICAM-1 for sICAM1-CT and sICAM-1-HM. Comparison of the $\mathrm{pK}_{\mathrm{i}}$ values showed that sICAM-1-CT and sICAM-1-HM bound to mouse astrocytes with similar affinities. The $\mathrm{pK}_{\mathrm{i}}$ values measured roughly corresponded to a binding affinity of 300 nM. For comparison, binding of human ICAM-1 to the $\alpha_{\mathrm{L}}$ I domain of its physiological ligand $\alpha_{L} \beta_{2}$ occurs with a $K_{d}$ of $1.5 \mathrm{mM}$, while binding to an engineered $\alpha_{\mathrm{L}}$ I domain, which is stabilized in a high-affinity open conformation by a disulfide linkage, occurs with a $\mathrm{K}_{d}$ of 150 to $360 \mathrm{nM}$ [42]. Therefore, the measured mouse sICAM-1 binding affinity for its unknown astrocytic receptor is comparable to the strongest physiological interactions known for human ICAM-1. The similar binding affinities of sICAM-1-CT and sICAM-1-HM for astrocytes show that the enhanced MIP-2-inducing activity of sICAM-1-CT is not due to a higher binding affinity for the astrocytic receptor. This result is consistent with our previous finding that the presence of complex-type $\mathrm{N}$-glycans on a protein is not sufficient to confer MIP-2-inducing activity, as both human AGP and vascular cell adhesion molecule-1 (VCAM-1) expressed in CHO cells were inactive in astrocytes [24].

Similar to our results, it has been shown that differently glycosylated heterodimeric glycoprotein hormones have similar binding affinities but different signaling activities [43]. Glycosylation at Asn52 of the $\alpha$ subunit plays a major role in signal transduction by human choriogonadotropin (hCG) and follicle-stimulating hormone (FSH) [44,45], but the binding affinity of FSH for its receptor is not affected by removal of the glycan at Asn52 [46]. The glycan at Asn52 of $\mathrm{hCG}$ is not directly involved in signal transduction, but in the stability of the heterodimer [47]. Complex-type N-glycans on sICAM-1 do not, however, appear to promote sICAM-1 oligomerization, since sICAM-1-CT and sICAM-1-HM were present in similar oligomeric states.

The observation of an increased signaling activity of sICAM-1-CT that was not due to an increased binding affinity to mouse astrocytes led us to assess whether it may be due to a more persistent effect on MIP-2 production and/or altered cellular distribution and processing. We found (i) that both the level and the duration of the MIP-2 production induced by sICAM-1-CT were increased, (ii) that the MIP-2 response to sICAM-1-CT was significantly more rapid, and (iii) that sICAM-1-CT accumulated at the plasma membranes of astrocytes, whereas sICAM-1-HM displayed a more diffuse cellular distribution. Thus, it appears that sialylated complex-type N-glycans on sICAM-1 promote its enhanced association with the cell surface of astrocytes and a more efficient signal transduction. Enhanced membrane association and signal transduction may be due to the ability of sICAM-1-CT to induce receptor clustering, which may be required for receptor activation and/or association with other proteins involved in the subsequent signaling pathway. In contrast, sICAM-1-HM may lack the ability to induce receptor clustering and this may result in its internalization and degradation. Alternatively, the more diffuse distribution of sICAM-1-HM could result from several factors, including altered binding kinetics and binding by a competing receptor or non-receptor protein. The latter possibility would be consistent with our finding of a higher number of binding 

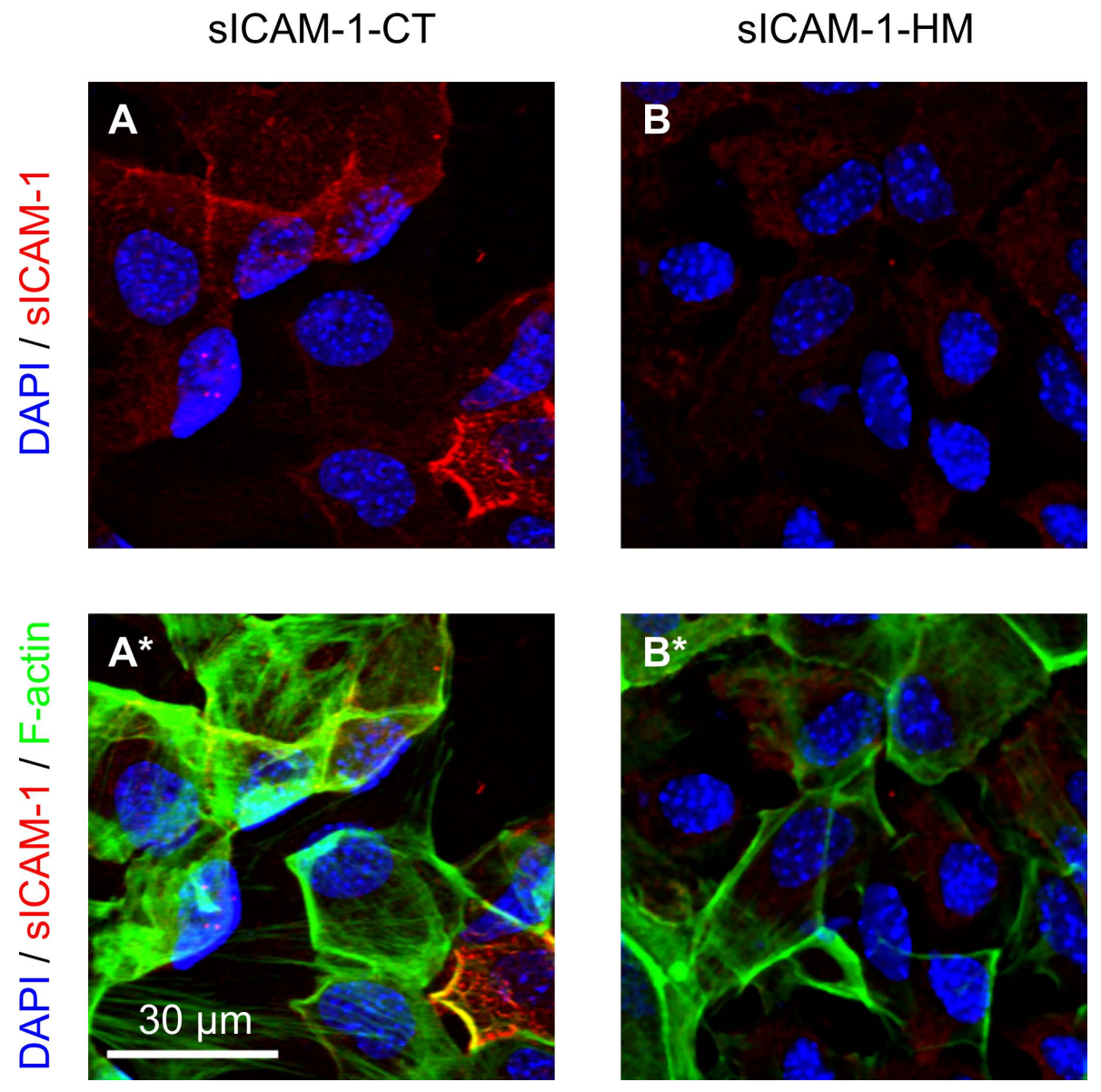

Fig. (5). sICAM-1-CT accumulates at plasma membranes of astrocytes. Primary mouse astrocytes were incubated with $500 \mathrm{nM}$ sICAM-1CT $\left(\mathbf{A}, \mathbf{A}^{*}\right)$ or sICAM-1-HM $\left(\mathbf{B}, \mathbf{B}^{*}\right)$ for $30 \mathrm{~min}$ at $37^{\circ} \mathrm{C}$. After washing, cells were fixed and permeabilized. Nuclei were stained with DAPI (blue), F-actin with Alexa Fluor ${ }^{\circledR} 660$ phalloidin (green), and sICAM-1 was detected by incubation with a biotinylated anti-sICAM-1 antibody followed by incubation with streptavidin-Cy3 (red). The amplification of the $\mathrm{Cy} 3$ channel was set to exclude background signal using a vehicle control which was stained omitting the first antibody, and was kept constant throughout the experiment. Figs. $\mathbf{A}^{*}$ and $\mathbf{B} *$ correspond to Figs. A and $\mathbf{B}$ additionally showing F-actin staining. One representative experiment out of two is shown.

sistent with our finding of a higher number of binding sites for sICAM-1-HM on mouse astrocytes.

Differential glycosylation may be an in vivo mechanism to fine-tune the kinetics and intensity of the cellular response induced by sICAM-1. The biological effects of sICAM-1 may therefore not only depend on its concentration, but also on the types of glycans it carries, which can be different in homeostasis versus disease conditions. In fact, protein glycosylation may be altered under inflammatory conditions. Proinflammatory stimuli have been shown to upregulate the expression of glycosyltransferases responsible for the biosynthesis of sialylated N-glycans. Exposure to TNF- $\alpha$ increases both the expression of the $\alpha 2,3$-sialyltransferases ST3Gal-III and ST3Gal-IV in the human bronchial mucosa and the expression of $\beta 1,4$-galactosyltransferase I in primary human endothelial cells $[48,49]$. Upregulation of $\alpha 2,3-$ sialyltransferase activity results in more complete sialylation of glycoproteins while enhanced activity of $\beta 1,4-$ galactosyltransferase I provides more terminal galactoses, which on their part are substrates for sialyltransferases. Altered $\alpha 2,3-, \alpha 2,6-$, and $\alpha 2,8$-sialylation of serum glycoproteins in mice was found in response to turpentine oil-induced inflammation [50]. By favoring the synthesis of sialylated complex-type $\mathrm{N}$-glycans, inflammatory stimuli such as TNF$\alpha$ may therefore indirectly enhance the intensity and duration of the signal elicited by SICAM-1 in astrocytes. Hence, the sICAM-1 produced under healthy conditions may only have a weak capacity to induce a short-lived chemokine production. After the onset of an inflammatory response as triggered by severe brain trauma, upregulation of proinflammatory cytokines may induce the production of fully sialylated and galactosylated sICAM-1 which can accumulate at astrocyte cell membranes and has the capacity to induce a strong and prolonged production of MIP-2. Future studies should be aimed at defining the glycosylation of endogenous SICAM-1 in cerebrospinal fluid of patients with severe brain trauma and at elucidating whether changes in glycosylation are induced by trauma.
ABBREVIATIONS
AGP
$=$ Human $\alpha-1$ acid glycoprotein
APTS
$=8$-aminopyrene-1,3,6-trisulfonic acid
BSA
$=$ Bovine serum albumin
$\mathrm{CHO}$ 


\begin{tabular}{|c|c|c|}
\hline DAPI & $=$ & $\begin{array}{l}\text { 4',6-Diamidine-2-phenylindole dihydro- } \\
\text { chloride }\end{array}$ \\
\hline FSH & $=$ & Follicle-stimulating hormone \\
\hline Fuc & $=$ & Fucose \\
\hline Gal & $=$ & Galactose \\
\hline GlcNAc & $=$ & $\mathrm{N}$-acetylglucosamine \\
\hline $\mathrm{hCG}$ & $=$ & Human choriogonadotropin \\
\hline $\begin{array}{l}\text { MALDI-TOF } \\
\text { MS }\end{array}$ & $=$ & $\begin{array}{l}\text { Matrix-assisted laser desorption/ } \\
\text { ionization time of flight mass spec- } \\
\text { trometry }\end{array}$ \\
\hline Man & $=$ & Mannose \\
\hline MIP-2 & $=$ & Macrophage inflammatory protein-2 \\
\hline NeuAc & $=$ & $\mathrm{N}$-acetylneuraminic acid \\
\hline PNGase F & $=$ & Peptide-N-glycosidase F \\
\hline (s)ICAM-1 & $=$ & $\begin{array}{l}\text { (soluble) intercellular adhesion mole- } \\
\text { cule-1 }\end{array}$ \\
\hline sICAM-1-CT & $=$ & $\begin{array}{l}\text { sICAM-1 containing sialylated complex- } \\
\text { type N-glycans }\end{array}$ \\
\hline sICAM-1-HM & $=$ & $\begin{array}{l}\text { sICAM-1 containing high mannose-type } \\
\text { N-glycans }\end{array}$ \\
\hline TNF- $\alpha$ & $=$ & Tumor necrosis factor- $\alpha$ \\
\hline VCAM-1 & $=$ & Vascular cell adhesion molecule- 1 \\
\hline
\end{tabular}

We thank Prof. Gerd Folkers, Collegium Helveticum, ETH Zurich, Switzerland, for his support and for many fruitful discussions. We are indepted to Prof. Vladimir Pliska, Collegium Helveticum, ETH Zurich, Switzerland, for his valuable help in analyzing the binding data and to Raimo Pellikka, Paul Scherrer Institute, Villigen, Switzerland, for helping us with protein iodination. We thank Prof. Heidi Wunderli-Allenspach and Maja Günthert, Institute of Pharmaceutical Sciences, ETH Zurich, Switzerland, for their kind advice and support with confocal laser scanning microscopy. W.L. is a Postdoctoral Researcher of the IWT-Flanders. N.C. is supported by a Marie Curie Excellence Grant of the EUFramework Programme 6.

\section{REFERENCES}

[1] van de Stolpe A, van der Saag PT. Intercellular adhesion molecule1. J Mol Med 1996; 74: 13-33.

[2] Rothlein R, Mainolfi EA, Czajkowski M, Marlin SD. A form of circulating ICAM-1 in human serum. J Immunol 1991; 147: 378893.

[3] Tsukada N, Matsuda M, Miyagi K, Yanagisawa N. Increased levels of intercellular adhesion molecule-1 (ICAM-1) and tumor necrosis factor receptor in the cerebrospinal fluid of patients with multiple sclerosis. Neurology 1993; 43: 2679-82.

[4] Chihara J, Yamamoto T, Kurachi D, Nakajima S. Soluble ICAM-1 in sputum of patients with bronchial asthma. Lancet 1994; 343: 1108.

[5] Dustin ML, Rothlein R, Bhan AK, Dinarello CA, Springer TA. Induction by IL 1 and interferon-gamma: tissue distribution, biochemistry, and function of a natural adherence molecule (ICAM-1). J Immunol 1986; 137: 245-54.

[6] Marotta G, Zagonel V, Pinto A. Induction of LFA-1/CD11a and ICAM-1/CD54 adhesion molecules on neoplastic B cells during in vivo treatment of chronic lymphocytic leukemia with interferon- $\alpha_{2}$. Blood 1993; 81: 267-69.
[7] Pleines UE, Stover JF, Kossmann T, Trentz O, MorgantiKossmann MC. Soluble ICAM-1 in CSF coincides with the extent of cerebral damage in patients with severe traumatic brain injury. $\mathrm{J}$ Neurotrauma 1998; 15: 399-409.

[8] Tessitore A, Pastore L, Rispoli A, et al. Two $\gamma$-interferon-activation sites (GAS) on the promoter of the human intercellular adhesion molecule (ICAM-1) gene are required for induction of transcription by IFN- $\gamma$. Eur J Biochem 1998; 258: 968-75.

[9] Otto VI, Heinzel-Pleines UE, Gloor SM, Trentz O, Kossmann T, Morganti-Kossmann MC. sICAM-1 and TNF- $\alpha$ induce MIP-2 with distinct kinetics in astrocytes and brain microvascular endothelial cells. J Neurosci Res 2000; 60: 733-42.

[10] Rancan M, Otto VI, Hans VH, et al. Upregulation of ICAM-1 and MCP-1 but not of MIP-2 and sensorimotor deficit in response to traumatic axonal injury in rats. J Neurosci Res 2001; 63: 438-46.

[11] Whalen MJ, Carlos TM, Kochanek PM, et al. Soluble adhesion molecules in CSF are increased in children with severe head injury. J Neurotrauma 1998; 15: 777-87.

[12] Diamond MS, Staunton DE, de Fougerolles AR, et al. ICAM-1 (CD54): a counter-receptor for Mac-1 (CD11b/CD18). J Cell Biol 1990; 111: 3129-39.

[13] Makgoba MW, Sanders ME, Ginther Luce GE, et al. ICAM-1 a ligand for LFA-1-dependent adhesion of B, T and myeloid cells. Nature 1988; 331: 86-8.

[14] Greve JM, Davis G, Meyer AM, et al. The major human rhinovirus receptor is ICAM-1. Cell 1989; 56: 839-47.

[15] Staunton DE, Merluzzi VJ, Rothlein R, Barton R, Marlin SD, Springer TA. A cell adhesion molecule, ICAM-1, is the major surface receptor for rhinoviruses. Cell 1989; 56: 849-53.

[16] Kusterer K, Bojunga J, Enghofer M, et al. Soluble ICAM-1 reduces leukocyte adhesion to vascular endothelium in ischemiareperfusion injury in mice. Am J Physiol 1998; 275: G377-80.

[17] Meyer DM, Dustin ML, Carron CP. Characterization of intercellular adhesion molecule-1 ectodomain (sICAM-1) as an inhibitor of lymphocyte function-associated molecule-1 interaction with ICAM-1. J Immunol 1995; 155: 3578-84.

[18] Rieckmann P, Michel U, Albrecht M, Brück W, Wöckel L, Felgenhauer K. Soluble forms of intercellular adhesion molecule-1 (ICAM-1) block lymphocyte attachment to cerebral endothelial cells. J Neuroimmunol 1995; 60: 9-15.

[19] Marlin SD, Staunton DE, Springer TA, Stratowa C, Sommergruber W, Merluzzi VJ. A soluble form of intercellular adhesion molecule-1 inhibits rhinovirus infection. Nature 1990; 344: 70-72.

[20] Gho YS, Kleinman HK, Sosne G. Angiogenic activity of human soluble intercellular adhesion molecule-1. Cancer Res 1999; 59 5128-32.

[21] Gho YS, Kim PN, Li HC, Elkin M, Kleinman HK. Stimulation of tumor growth by human soluble intercellular adhesion molecule-1. Cancer Res 2001; 61: 4253-57.

[22] McCabe SM, Riddle L, Nakamura GR, et al. sICAM-1 enhances cytokine production stimulated by alloantigen. Cell Immunol 1993; 150: 364-75.

[23] Otto VI, Gloor SM, Frentzel S, et al. The production of macrophage inflammatory protein-2 induced by soluble intercellular adhesion molecule- 1 in mouse astrocytes is mediated by src tyrosine kinases and p42/44 mitogen-activated protein kinase. J Neurochem 2002; 80: 824-34.

[24] Otto VI, Schürpf T, Folkers G, Cummings RD. Sialylated complextype N-glycans enhance the signaling activity of soluble intercellular adhesion molecule-1 in mouse astrocytes. J Biol Chem 2004; 279: 35201-209.

[25] Lub M, van Kooyk Y, Figdor CG. Ins and outs of LFA-1. Immunol Today $1995 ; 16: 479-83$.

[26] Shrikant P, Benveniste EN. The central nervous system as an immunocompetent organ: role of glial cells in antigen presentation. J Immunol 1996; 157: 1819-22.

[27] Diamond MS, Staunton DE, Marlin SD, Springer TA. Binding of the integrin Mac-1 (CD11b/CD18) to the third immunoglobulinlike domain of ICAM-1 (CD54) and its regulation by glycosylation. Cell 1991; 65: 961-71.

[28] Callewaert N, Geysens S, Molemans F, Contreras R. Ultrasensitive profiling and sequencing of $\mathrm{N}$-linked oligosaccharides using standard DNA-sequencing equipment. Glycobiology 2001; 11: 275-81.

[29] Morganti MC, Taylor J, Pesheva P, Schachner M. Oligodendrocyte-derived J1-160/180 extracellular matrix glycoproteins are ad- 
hesive or repulsive depending on the partner cell type and time of interaction. Exp Neurol 1990; 109: 98-110.

[30] Merril CR. Gel-staining techniques. Methods Enzymol 1990; 182: 477-88.

[31] Blum H, Beier H, Gross HJ. Improved silver staining of plant proteins, RNA and DNA in polyacrylamide gels. Electrophoresis 1987; 8: 93-9.

[32] Martin de Llano JJ, Garcia-Segura JM, Gavilanes JG. Selective silver staining of urease activity in polyacrylamide gels. Anal Biochem 1989; 177: 37-40.

[33] Hedrick JL, Smith AJ. Size and charge isomer separation and estimation of molecular weights of proteins by disc gel electrophoresis. Arch Biochem Biophys 1968; 126: 155-64.

[34] Bryan JK. Molecular weights of protein multimers from polyacrylamide gel electrophoresis. Anal Biochem 1977; 78: 513-19.

[35] Otto VI, Damoc E, Cueni LN, et al. N-glycan structures and Nglycosylation sites of mouse soluble intercellular adhesion molecule-1 revealed by MALDI-TOF and FTICR mass spectrometry. Glycobiology 2006; 16: 1033-44.

[36] Chen W, Stanley P. Five Lec1 CHO cell mutants have distinct Mgat1 gene mutations that encode truncated $\mathrm{N}$-acetylglucosaminyltransferase I. Glycobiology 2003; 13: 43-50.

[37] Stanley P, Chaney W. Control of carbohydrate processing: the lec1A CHO mutation results in partial loss of $\mathrm{N}$ acetylglucosaminyltransferase I activity. Mol Cell Biol 1985; 5: 1204-11.

[38] Rovati GE. Ligand-binding studies: old beliefs and new strategies. Trends Pharmacol Sci 1998; 19: 365-69.

[39] Burudi EM, Riese S, Stahl PD, Régnier-Vigouroux A. Identification and functional characterization of the mannose receptor in astrocytes. Glia 1999; 25: 44-55.

[40] Bragonzi A, Distefano G, Buckberry LD, et al. A new Chinese hamster ovary cell line expressing $\alpha 2,6$-sialyltransferase used as universal host for the production of human-like sialylated recombinant glycoproteins. Biochim Biophys Acta 2000; 1474: 273-82.

[41] Mühlenhoff M, Manegold A, Windfuhr M, Gotza B, GerardySchahn R. The impact of N-glycosylation on the functions of polysialyltransferases. J Biol Chem 2001; 276: 34066-073.
[42] Shimaoka M, Xiao T, Liu JH, et al. Structures of the $\alpha \mathrm{L}$ I domain and its complex with ICAM-1 reveal a shape-shifting pathway for integrin regulation. Cell 2003; 112: 99-111.

[43] Valove FM, Finch C, Anasti JN, Froehlich J, Flack MR. Receptor binding and signal transduction are dissociable functions requiring different sites on follicle-stimulating hormone. Endocrinology 1994; 135: 2657-61.

[44] Flack MR, Froehlich J, Bennet AP, Anasti J, Nisula BC. Sitedirected mutagenesis defines the individual roles of the glycosylation sites on follicle-stimulating hormone. J Biol Chem 1994; 269: 14015-20.

[45] Matzuk MM, Keene JL, Boime I. Site specificity of the chorionic gonadotropin N-linked oligosaccharides in signal transduction. J Biol Chem 1989; 264: 2409-14.

[46] Bishop LA, Robertson DM, Cahir N, Schofield PR. Specific roles for the asparagine-linked carbohydrate residues of recombinant human follicle stimulating hormone in receptor binding and signal transduction. Mol Endocrinol 1994; 8: 722-31.

[47] Heikoop JC, van den Boogaart P, de Leeuw R, Rose UM, Mulders JW, Grootenhuis PD. Partially deglycosylated human choriogonadotropin, stabilized by intersubunit disulfide bonds, shows full bioactivity. Eur J Biochem 1998; 253: 354-56.

[48] Delmotte P, Degroote S, Lafitte JJ, Lamblin G, Perini JM, Roussel P. Tumor necrosis factor alpha increases the expression of glycosyltransferases and sulfotransferases responsible for the biosynthesis of sialylated and/or sulfated Lewis $\mathrm{x}$ epitopes in the human bronchial mucosa. J Biol Chem 2002; 277: 424-31.

[49] Garcia-Vallejo JJ, van Dijk W, van Die I, Gringhuis SI. Tumor necrosis factor- $\alpha$ up-regulates the expression of $\beta 1,4$ galactosyltransferase I in primary human endothelial cells by mRNA stabilization. J Biol Chem 2005; 280: 12676-682.

[50] Yasukawa Z, Sato C, Kitajima K. Inflammation-dependent changes in $\alpha 2,3-, \alpha 2,6-$, and $\alpha 2,8$-sialic acid glycotopes on serum glycoproteins in mice. Glycobiology 2005; 15: 827-37.

(C) Schürpf et al.; Licensee Bentham Open .

This is an open access article licensed under the terms of the Creative Commons Attribution Non-Commercial License (http://creativecommons.org/licenses/by-nc/3.0/) which permits unrestricted, non-commercial use, distribution and reproduction in any medium, provided the work is properly cited. 